\title{
EL PRONOMBRE VOSOTROS BAJO EL REINADO DE LOS BORBONES
}

\section{THE PRONOUN VOSOTROS UNDER THE BOURBONS}

\author{
Víctor LARa Bermejo \\ Universidad de Cádiz \\ viktoresc@hotmail.com \\ orcid: 0000-0002-1068-8553
}

Resumen: El pronombre vosotros encierra todavía enigmas en lo que se refiere a su recorrido histórico en las distintas variedades del español. A pesar de haber cierto consenso sobre el carácter marcado de esta forma a ambos lados del Atlántico durante varios siglos, sigue sin estar claro qué llevó a la Península Ibérica a revertir su uso, a la vez que América eliminaba paulatinamente los pocos que poseía en tal variedad. El presente artículo pretende dar cuenta de la vigencia de este pronombre en la primera etapa del reinado de los Borbones en España y comprobar qué capas sociales lo empleaban, de qué áreas geográficas provenían y en qué contextos recurrían a éste.

Palabras clave: pronombres de tratamiento; español peninsular;

siglos XVIII y XIX; cartas; vosotros.

Abstract: There is still much mystery surrounding the historical development of the pronoun vosotros in the different spheres of the Spanish language. Although scholars agree that it constitutes a striking feature of the language on both sides of the Atlantic, it is still unclear what prompted the Iberian Peninsula to revert to using it, whilst America gradually eliminated the few uses of it that it still possessed. In this article, I aim to account for the continued use of this pronoun during the first period of Bourbon rule in Spain and to identify in which social media and geographical areas it was to be found and in what contexts it was used.

Keywords: pronouns of address; Peninsular Spanish; $18^{\text {th }}$ and $19^{\text {th }}$ centuries; letters; vosotros.

Recepción: 5 de diciembre de 2019; aceptación: 3 de septiembre de 2020.

D.R. () 2022. Nueva Revista de Filología Hispánica Licencia Creative Commons Attribution-NonCommercial (CC BY-NC) 4.0 International 
INTRODUCCIÓN*

El pronombre vosotros sigue siendo actualmente uno de los grandes enigmas del español. Frente a la cantidad de estudios que versan sobre el tuteo, voseo o la evolución de vuestra $(s)$ merce$d(e s)$ en usted(es), el surgimiento y posterior uso de vosotros cuenta con escasos trabajos que se ocupen de su historia y verdadera vigencia a ambos lados del Atlántico. Su origen proviene de la lexicalización de vós otros, en una época (el siglo XIV) en la que el pronombre vós empezaba a presentar diversos problemas: dejaba de connotar el mismo grado de cortesía que en siglos anteriores y tenía una polivalencia pareja a la del francés vous (Tabla 1).

\section{TABLA 1}

Pronombres de tratamiento en el español medieval

\begin{tabular}{lcc}
\hline & Informal $(T)$ & Formal $(V)$ \\
\hline Singular & Tú +2 sg. & Vós $+2 \mathrm{pl}$. \\
Plural & Vós $+2 \mathrm{pl}$. & Vós $+2 \mathrm{pl}$. \\
\hline
\end{tabular}

Como se puede observar en la Tabla 1, el pronombre vós constituía el no marcado y podía surgir en numerosos contextos, lo que llevó a que se apreciara como elemento de poca cortesía. A finales de la Edad Media, empezaron a nacer numerosos sintagmas nominales compuestos por posesivo más sustantivo abstracto, como vuestra alteza, vuestra señoría, entre otros, pero fue vuestra merced, y su plural, el que pronto se generalizó como nueva estrategia de formalidad y distancia (Tuten 2008). Contemporáneamente a este suceso, la secuencia vós otros y su lexicalización en vosotros se fueron asentando en todo el español peninsular a partir de un claro contagio con el catalán vosaltres (Fernández-Ordóñez 2011; Gomila Albal 2016). Esta lengua exhibía el mismo patrón pragmático que el reproducido en la Tabla 1 y optó por la innovación vosaltres un siglo antes de que lo hiciera el español.

* Esta investigación ha sido realizada en el marco del programa Horizon 2020, financiado por la Comisión Europea, bajo un proyecto Marie Slodowska Curie Individual Fellowship, titulado "The politeness system and the emergence of a Sprachbund". 
Además de los problemas diafásicos que comportaba vós, la generalización de vosotros sirvió para desambiguar el referente, ya que sólo podía ser plural, y también ayudó a conformar un sistema de cortesía llamado "simétrico", en el que vosotros se iba oponiendo a vuestras mercedes — o sus formas más gramaticalizadas - para la informalidad e intimidad, y la formalidad, respectivamente (García et al. 1990; De Jonge y Nieuwenhuijsen 2006), como se aprecia en la Tabla 2.

TABLA 2

Formas de tratamiento en el español peninsular moderno

\begin{tabular}{lcl}
\hline & Informal $(T)$ & \multicolumn{1}{c}{ Formal $(V)$} \\
\hline Singular & Tú $+2 \mathrm{sg}$. & $\begin{array}{l}\text { Vuestra merced }+3 \mathrm{sg} . \\
\text { Otros honoríficos }\end{array}$ \\
Plural & Vosotros $+2 \mathrm{pl}$. & $\begin{array}{l}\text { Vuestras mercedes }+3 \mathrm{pl} . \\
\text { Otros honoríficos }\end{array}$ \\
\hline
\end{tabular}

Sin embargo, esta supuesta simetría es mucho más reciente, a tenor de las investigaciones que se han realizado para el empleo de vuestras mercedes-ustedes, así como de los últimos trabajos que versan sobre vosotros. El sistema de cortesía que imperaba en la Edad Media y en la Edad Moderna - era que suele abarcar desde el siglo XVI hasta el siglo XVIII- es el llamado jerárquico y deferencial (Scollon \& Scollon 1995). Bajo este marco pragmático, los hablantes tienden a mantener una relación de distancia, si entre ellos existe el mismo poder - como entre dos amigos, dos colegas de profesión o dos individuos de la misma clase social—, o asimétrica, si no comparten esta característica - de superior a subordinado o entre miembros de la familia que no se encuentren en el mismo escalafón, como padres e hijos, sobrinos y tíos, etc. En consecuencia, los pronombres más utilizados, al menos hasta el siglo XVIII, eran los que se asocian con las formas V (según la taxonomía de Brown \& Gilman 1960), que, en el caso del español de la época, se circunscriben a vuestra $(s)$ merced(es)-usted(es). Por tanto, el uso de vosotros - y, en consonancia, tú - estaba muy constreñido a situaciones en las que un individuo tuviera poder sobre su público.

A todo ello hay que añadir el carácter sintáctico de usted(es). A tenor de lo descrito por De Jonge y Nieuwenhuijsen (2006), 
a finales del siglo XVII se generaliza tal gramaticalización, por lo que durante las centurias de 1500 y 1600 vuestra $(s)$ merce$d(e s)$ no constituye verdaderamente un pronombre. Este dato es de vital importancia, puesto que no podemos considerar la existencia de un verdadero binomio pronominal encarnado en vosotros-ustedes hasta el siglo XVIII. Previamente a este hecho, vosotros convivía con sintagmas nominales, entre los más usuales, vuestras mercedes, el cual funcionaba sintácticamente como cualquier otro sintagma nominal, al estilo de señores. Asimismo, el surgimiento de dicho honorífico no llevó aparejada la 3pl. por defecto, ya que Calderón Campos (2000) documenta numerosos casos en los que vuestra $(s)$ merced(es) podía combinarse con flexión de 2pl. Es más, todavía incluso en el siglo xviıI, Fernández Martín (2012) muestra este tipo de hibridaciones, aunque ya con la forma ustedes en toda la Península Ibérica. Queremos enfatizar el matiz imprescindible sobre la conversión a pronombre de vuestras mercedes, ya que, como bien demuestra García Godoy (2015), la cantidad de variantes en la gramaticalización de vuestra(s) merced(es) a usted(es) que argumenta Pla Cárceles (1923) no responde a la verdadera casuística que se hallaba en el ámbito oral. La autora certifica que las alternativas que Pla Cárceles expone sólo aparecen en la literatura, pero no se corresponden con los usos que exhiben otros géneros más fieles al registro oral. Así, García Godoy (2016) aduce que las gramaticalizaciones de vuestra merced se reducen a dos: vusted y usted, con sus correspondientes formas plurales, sin que hubiese ninguna distinción sociolingüística entre ambas variantes.

Hemos indicado que el valor de vosotros es, desde su origen, una forma $\mathrm{T}$, o sea, un pronombre asociado a la intimidad, la informalidad, la solidaridad. Sin embargo, tanto Calderón Campos (2019) como Bertolotti (2020) plantean que vosotros ha tenido siempre un doble valor de cercanía y distancia, ya que podía erigirse como una forma retórica y elevada. Es por ello que aparece comúnmente en arengas militares, en el lenguaje eclesiástico o en ceremonias solemnes. Para los estudiosos, esta funcionalidad de vosotros es contraria a la de una forma $\mathrm{T}$, ya que marca distancia; a nuestro juicio, sin embargo, no hay verdadera dualidad. Como forma T, sirve tanto para la solidaridad entre pares como para el trato de superior a inferior, toda vez que, en un sistema jerárquico, quien está por debajo suele tratar mediante una estrategia $\mathrm{V}$ a quien tiene por encima, mientras que este último opta por tratar de $\mathrm{T}$ a quien se encuentra en 
una posición inferior (Scollon \& Scollon 1995). En una arenga militar, quien está por encima de su público es consecuente con tal jerarquía al elegir una forma $\mathrm{T}$ para hablarles; lo mismo podemos argüir en el ámbito religioso, ya que el sacerdote que se dirige a sus feligreses, lo hace en nombre de Dios, quien está por encima de ellos; igualmente, el político que habla a sus conciudadanos ostenta un cargo que está por encima de todos ellos y que decide sobre sus vidas. En todos estos supuestos, vosotros actúa como $\mathrm{T}$.

En definitiva, la Edad Contemporánea es el momento a partir del cual podemos establecer una verdadera oposición pronominal vosotros-ustedes, que se irá diluyendo en el caso de América a favor del último, y asentando en España a tenor de los datos de que disponemos del siglo xx (Tabla 3).

\section{TABLA 3}

Pronombres de tratamiento en el español peninsular contemporáneo

\begin{tabular}{lll}
\hline & Informal $(T)$ & Formal $(V)$ \\
\hline Singular & Tú $+2 \mathrm{sg}$. & Usted $+3 \mathrm{sg}$. \\
Plural & Vosotros $+2 \mathrm{pl}$. & Ustedes $+3 \mathrm{pl}$. \\
\hline
\end{tabular}

Lara Bermejo (2018) da cuenta de la realidad dialectal de la Península Ibérica de la primera mitad del siglo xx y demuestra que la dicotomía vosotros-ustedes, tal cual se conoce hoy día, con sus respectivas concordancias, estaba completamente establecida en España, salvo en Andalucía occidental, donde ustedes representaba la única posibilidad, aunque con fluctuaciones entre la 2pl. y la 3 pl. Por tanto, son los siglos XVIII y xix los decisivos en España a la hora de favorecer el paradigma actual, pues, recordemos, Fernández Martín (2012) corrobora que, todavía a principios del siglo XviII, la oposición vosotros-ustedes no estaba nada clara en España, como tampoco lo estaba la concordancia que inducía ustedes. Además, según la autora, es a partir de 1700 cuando se establece la distinción entre Andalucía occidental y el resto de España.

Con el fin de obtener datos que reflejen la realidad oral y dialectal de la España dieciochesca y decimonónica y, concretamente, que muestren la extensión de vosotros, hemos extraído datos de un corpus epistolar que da cuenta de los distintos 
tratamientos que se atestiguaban entre 1700 y 1833 . A continuación, procederemos a describirlos.

\section{Corpus y Metodología}

El corpus del cual hemos obtenido los datos es Post scriptum. Se trata de una recopilación de cartas privadas en español y portugués europeos desde el siglo Xvi hasta el siglo XIX, realizada en el marco de un proyecto europeo coordinado por la investigadora del Centro de Lingüística de Lisboa, Rita Marquilhas. Las misivas pertenecen a diferentes estratos sociales, si bien abundan las clases elevadas y letradas, y se encuentran disponibles en diversos formatos con transcripción normalizada, así como en su formato original. La herramienta empleada es pionera en este aspecto, puesto que recoge de forma exhaustiva millares de cartas que abarcan varios siglos y dos lenguas bajo un mismo espacio geográfico: la Península Ibérica.

Hemos analizado 1409 cartas que van de los años 1700 a 1833 - hasta ahora, no hay misivas para el español que cubran un período posterior en el siglo xix - y clasificado los datos a partir de dos parámetros: uno lingüístico y otro sociolingüístico. Para el primero, dividimos las ocurrencias según su carácter sintáctico (sujeto, término de sintagma preposicional, clítico, posesivo y verbo); para el segundo, clasificamos la relación que se establece entre remitente y destinatario, así como la profesión, la clase social y el origen geográfico, si se conoce. La taxonomía aplicada ha permitido averiguar qué vigencia tenía vosotros durante los casi primeros 150 años tras la instauración de la dinastía borbónica y qué comportamiento sintáctico y de concordancia tenía con los elementos que dependen de este pronombre. Asimismo, hemos podido descubrir si había hibridaciones al estilo del voseo hispanoamericano y qué perfil de hablante recurría a este pronombre y en qué contextos. En la Tabla 4 presentamos los números totales.

Ante todo, cabe resaltar la escasez de datos para el pronombre tónico, ya sea en su versión de sujeto como de término de sintagma preposicional — de las 500 cartas del siglo xIX, no hay una que dé un solo ejemplo de vosotros como sujeto. No es en absoluto extraño, ya que la explicitación del sujeto en español se constriñe a contextos desambiguadores o contrastivos, por lo que son los demás elementos sintácticos los que ayudan 
TABLA 4

Ocurrencias de "vosotros" y elementos concordantes

\begin{tabular}{lcccrcrr}
\hline & Sujeto & $\begin{array}{c}\text { Sintagma } \\
\text { preposicional }\end{array}$ & Reflexivo & OD & OI & Posesivo & Verbo \\
\hline Siglo xviII & 6 & 7 & 7 & 28 & 20 & 61 & 82 \\
$1800-1833$ & 0 & 10 & 4 & 3 & 14 & 25 & 35 \\
Total & 6 & 17 & 11 & 31 & 34 & 86 & 117 \\
\hline
\end{tabular}

a dilucidar la vigencia de vosotros en el panorama del español dieciochesco y decimonónico.

De las cartas que explícitamente utilizan vosotros como pronombre, en la Tabla 5 hallamos la siguiente relación según los perfiles sociolingüísticos de los interlocutores:

TABLA 5

Relación de interlocutores en el uso de "vosotros"

\begin{tabular}{lll}
\hline Profesión & Clase social & Origen geográfico \\
\hline Religiosos: 3 & Baja: 13 & Levante: 4 \\
Profesionales libres: 6 & Otros: 8 & Centro-norte: 16 \\
Militares: 6 & Total: 21 & Centro-sur \\
Total: 15 & & (no Andalucía): 2 \\
& & Total: 22 \\
\hline
\end{tabular}

La Tabla 5 muestra que la procedencia de hablantes que utilizan explícitamente vosotros se circunscribe al centro-norte peninsular, salvo cuatro hablantes del área levantina catalanoparlante y otros dos del español meridional, aunque no andaluz. Además, las relaciones entre los participantes son de igualdad dentro del ámbito familiar (hermanos, primos) o de asimetría descendente, ya sea en la familia (progenitor a hijo) o en un ámbito social más amplio, aunque en esta tabla no hemos detallado tanta casuística, ya que se puede encontrar en la misma fuente Post scriptum y se irá desglosando en los ejemplos que ofrezcamos. El corpus no da siempre toda la información de profesión y clase social de todos los participantes, por lo que las desigualdades numéricas sobre este respecto responden a tal carencia. En cualquier caso, observamos una mayoría de 
individuos pertenecientes a un estrato social bajo y otros ocho hablantes cuyas profesiones no terminan por aclarar la verdadera condición socioeconómica, ya que en ese grupo entran algunos militares y profesionales libres. Vemos igualmente que, a pesar de la cantidad de misivas que figura en el corpus, el número total de hablantes que recurre a la forma tónica vosotros es ínfimo, entre otras cosas, por la escasa probabilidad de que se dirijan a una pluralidad de interlocutores.

En cualquier caso, la cantidad de ocurrencias de pronombre y formas concordantes es exigua si lo comparamos sólo con el número de veces que se explicita la forma ustedes o alguna de sus variantes abreviadas, en cuyo caso hallamos 465 ocurrencias (Tabla 6).

TABla 6

Ocurrencias de "ustedes" y sus variantes

\begin{tabular}{lccc}
\hline & Ustedes & VMS & Vuestras mercedes \\
\hline Siglo XVIII & 70 & 352 & 2 \\
$1800-1833$ & 28 & 13 & 0 \\
Total & 98 & 365 & 2 \\
\hline
\end{tabular}

La Tabla 6 tan sólo especifica la presencia evidente de ustedes o alguna de sus variantes que, en el caso de este corpus, se reducen a la abreviación VMS y, de manera anecdótica, al sintagma vuestras mercedes. Al no estar esta herramienta etiquetada para poder discernir una tercera persona del plural semántica de una que connote cortesía, resulta inabarcable cuantificar los resultados referidos a pronombres átonos, posesivos y verbos. Sin embargo, el mismo cotejo de la forma tónica en una lengua pro drop como el español nos da una pista de la verdadera incidencia: a las 23 ocurrencias de pronombre tónico vosotros en 133 años se oponen 465 de ustedes para el mismo lapso temporal. Como indicábamos más arriba, las formas V eran las no marcadas. A pesar de esta desigualdad numérica, los resultados que ofrece el corpus permiten vislumbrar los cambios que se estaban dando en España. A continuación, procedemos a describir los datos para, más tarde, comentarlos y analizarlos. 


\section{Resultados}

Como indicamos en el apartado anterior, las ocurrencias de pronombre tónico han sido exiguas en comparación con otros elementos flexivos. Para el primero de los siglos, la primera ocurrencia de vosotros que hallamos data de 1708 , a la que siguen otras en $1709,1710,1746,1751$ y 1770 . En (1-3) vemos extractos del uso de vosotros, así como una concordancia sistemática en 2 pl. en el verbo:

(1) Sabe Dios como me hallo y que estoy más pobre que nunca creí verme y que necesito yo misma más que no él, aunque si lo tuviera lo quitara a mí porque él valiera. Pero cuando creí que tú y Pepe y Bartolomé me enviaseis algo, no me tenéis más en la memoria que si nunca fuerais hijos míos... Bien sé que tienes hijos y mujer, mas también sé que tienes gran caudal y que gastas en pleitos mucho. Mejor te fuera lo que gastas en pleitos remitirlo a esta pobre madre que no tiene quien de ella se duela si vosotros no lo hacéis; y más tú, que puedes y no quieres, que los otros dos pobres acaso no lo tendrán (carta de María de la Madrid y Noriega a su hijo, Pedro Mendoza y Escalante, fechada el 6 de agosto de 1710).

(2) Buen testimonio es de esto el último entre nosotros: nuestro, y si no de otro a lo menos, mi hermano Bartolomé, que tú y José ya no le daréis este trato... Digo que por ser último en el nacer halló tan poco que merecer entre vosotros que a desconfianza de vosotros mismos tomó a partido el peregrinar tierras bárbaras e incógnitas, de modo que ni vosotros ni los que de ese reino vienen dan mejor noticia que la de haberse entrado por lo más remoto de esos reinos y que de él ni tú ni tu hermano José sabéis cosa alguna (carta de Francisco de Mendoza y Escalante a Pedro de Mendoza y Escalante, fechada el 25 de julio de 1710).

(3) Creo que entre extraños los encontrará, pues sé que el marido de María de Matauco le ha dado tres mil reales y con tal bizarría que no quería tomar prendas, pero como tiene hijos que pueden saltar se las ha hecho tomar... Él les dio cuenta de todo el Día de las Ánimas y a él se negaron: de que no podían dar nada. Hoy es el día que no se han hecho dueños con Mónica... Cosas tan irregulares que ni sé a qué atribuirlo, sino que son modos que Dios busca para ejercicio, pues esto de no hacerse cargo... Que por vosotras no se ha empeñado la casa y sois las primeras acreedoras (carta de 
Rosario de Rivas a María Polonia de Rivas, fechada el $1^{\circ}$ de noviembre de 1746).

No hay duda de que vosotros y la $2 p l$. hacen referencia a una pluralidad de alocutarios que siempre están por debajo en la escala jerárquica, ya que es la estrategia que el progenitor utiliza para dirigirse a sus hijos (1), o surge también para el trato recíproco entre miembros de la familia que comparten una misma categoría, como entre hermanos (2-3). Sin embargo, algunas de las ocurrencias presentan ciertas ambigüedades en cuanto al verdadero número de interlocutores a los que se dirige la forma vosotros. Sin ir más lejos, en una epístola fechada en 1709, escrita a su hermano Gerónimo López, Bernardo López expresa:

(4) En ésta tuve nuevas en como llegasteal Duero enfrente de Vilarinho y preguntaste por noso padre y por todos los demás, de que me parece te dieron lacón. Y pides te escribiese. Así lo hago, ya que tú no tuviste la ocasión de nos dar cuenta de $t u$ vida ni de los demás hermanos por ser cosa que deseábamos, pues ha tanto tiempo que no hemos tenido noticias de vosotros aunque lo hemos preguntado a muchos que a ésta vienen, cosa que tú ni tu hermano no habrá procurado... Y así lo que te pido es que, si ésta fuere a tu mano, que merezca respuesta avisándome de todo lo que os ha sucedido y de cómo os va, que siempre lo estimaré de todo buen suceso. Y así, pues tengo esta ocasión, también quiero darte cuenta de mi vida... Y noso pai está ya muy viejo y acabado, pero anda bueno y gordo y te manda su bendición con la de Dios, que a todos nos alcance. Y dice que le escribáis, que ya tiene vontade de saber de vosotros, y que le digas adónde tenéis vuestra vivienda y si ha muerto alguien; y Donisia, si ha tomado estado. De todo esperamos buenas noticias nos mandes (fechada el 3 de junio de 1709).

No obstante, estas aparentes ambivalencias en el trato han de ponerse en contexto con el género al que nos enfrentamos. En las cartas escritas entre familiares, era habitual que un progenitor escribiera a un hijo como único destinatario - o un hermano a otro- y que, a lo largo del discurso, fuera cambiando de alocutarios en función del tema del que hablaba. Si analizamos (4), el remitente a veces se dirige a su hermano ("lo que te pido") y, a veces, los referentes son más miembros de la familia ("dice que le escribáis"). Esta ambigüedad no era tal para el destinatario y no supone prueba de que vos se siguiera empleando como tratamiento singular. Además, el trato es congruente en 
singular y plural, puesto que el remitente utiliza una forma $\mathrm{T}$ encarnada en tú y la 2 sg. o vosotros y la $2 \mathrm{pl}$. Observamos el mismo comportamiento en (5) y (6):

(5) Por Dios y por María Santísima te ruego le envíes para desempeñarse, que está si no perdido. Y corriendo de cuenta de Francisco, si a él le envías el dinero, él lo desempeñará, que también está sintiendo ver la hacienda de $t u$ padre en tales poderes y dice que si Dios a ti y a los hermanos da vida, que no lo gozarán mucho tiempo. Facundo y él ahora están reñidos... Y lo que yo más advierto en él es ser buen cristiano y que teme mucho a Dios, y que le hará Dios bien por eso. Y conmigo no riñe si no es porque no sirvo a Dios como debo y porque no doy mucho de limosna. Cosas le veo hacer que me admira y así cada día le digo que os encomiende a Dios... No heredaron los hijos de aquéllas más bienes ni tantos como vosotros de mí heredarais y de vuestro padre, que sea en gloria, si los quisierais y aunque otros no heredaseis. Sabéis que en la montaña en donde nacisteis no han nacido hijos que heredasen de sus padres mejor calidad ni más libre de la menor sospecha, porque vuestro padre, yo sin comercios, sin oficios y sin tratos os criábamos en el corto tiempo que me hizo compañía. Mis padres y vuestros abuelos terceros y cuartos abuelos de sola su renta se alimentaban, sin... sospecha ni presunción de oficio; y de sola nuestra renta os alimentamos vuestro padre y yo (de María de Madrid y Noriega a su hijo, 6 de agosto de 1710).

(6) No ignorarás que en el día gran parte del patrimonio de Caramany se halla segrestado y que sólo poseo yo, para lo que el tribunal me ha considerado para una decente manutención o alimentos. Tengo noticia que mi señora madre ha dimitido en poder de la Real Sala los bienes de casa Ros, solicitando el que su excelencia disponga de ellos y de las detracciones a que se consideran sujetos. Discurro que os comprenderán también a vosotros las providencias que en consecuencia resultaren. Y cuando eso faltase, no son mis entrañas para veros padecer, aunque me figuro que jamás podrá dejaros en ese estado mi señora madre, a favor de quien habéis vosotros hecho las renuncias de vuestros derechos.

Cata ahí cuanto puedo decirte en contexto de tus solicitudes, apreciándote la propensión que demuestras en servirme y correspondiéndote de mi parte con fina ley, como que soy $t u$ hermano de corazón (de Salvador Company y Fontdevila a su hermano, fechada el 10 de septiembre de 1770). 
En (5-6) se corrobora un uso sistemático de pronombres informales, ya sean tuteantes cuando se dirige a un solo interlocutor o en el empleo de vosotros cuando el destinatario es plural. Lo mismo se aprecia en (7-14):

(7) Yasí lo que te pido es que, si ésta fuere a $t u$ mano, que merezca respuesta avisándome de todo lo que os ha sucedido y de cómo os va, que siempre lo estimaré de todo buen suceso (carta de Bernardo López a su hermano Gerónimo López, fechada el 3 de junio de 1709).

(8) Hijo. Será para mí de mucho consuelo el que ésta te halle con salud en compañía de mi hija y tu mujer y los nietos, que de $t u$ parte no puedo saber si la gozáis o no. Pero no me he descuidado ni me descuido en adquirirla de ti y de los demás hijos por los que de allá vienen. Si no me engañan, que yo lo temo, sé que la gozáis, aunque por carta tuya ni de los demás no puedo merecer este consuelo. Y en esto bien creo eres tú la causa, que, a no ser así, Pepe y Bartolomé, ya que no me socorrieran con otra cosa, no me dejaran de atender con sus cartas. No sé en qué consiste el que así me hayáis olvidado (carta de María de la Madrid y Noriega a su hijo Pedro de Mendoza y Escalante, fechada el 6 de agosto de 1710).

(9) José Antonio o Pepe Polanco. Con el mozo mío, quien se va sin detenerse, os envío ese pedimento que me envían la Manuela y Teniente. Verlo y antes de darlo a Eugenio Martínez consultarlo con don Julián Monzón (pues sabrá éste a qué ha vuelto Romero a Mazarulleque) y don Julián (carta de Juan José Aranda, cura, a su hermano, José Antonio Aranda, fechada entre 1756 y 1757$)$.

(10) Y te advierto que yo a mi compadre de $t u$ madre y de $t i$ nada le he dicho, que a todo me he dado por desentendido, que ni a $t i$ ni a $t u$ madre para nada os he tomado en boca. Conque, como llevo dicho, mi compadre me ha dicho el que vaya a su casa. Y yo no me determino hasta no saber si tú eres gusta (carta de Vicente Salazar a Isabel Trujillo, a quien pretende, fechada entre 1766 y 1771).

(11) Amigo, me he alegrado mucho de lo que me envías a decir, que estás trabajando en la huerta de su ilustrísima, y me alegro mucho de que tengáis qué comer. Pero..., como amigo y amiga, que no os dejéis llevar de otros, que bien sabéis que 
estáis fuera de tierra y tengo entendido que en esa tierra tienen envidia al que se aplican $[s i c]$ a ganar de comer (carta de Manuel de Pablo a su primo, Pedro Escribano, fechada el 16 de mayo de 1793).

(12) José Antonio o Pepe Polanco. Con el mozo mío, quien se va sin detenerse, os envío ese pedimento que me envían la Manuela y Teniente. Verlo y antes de darlo a Eugenio Martínez consultarlo con don Julián Monzón (pues sabrá éste a qué ha vuelto Romero a Mazarulleque) y don Julián... Y aun si vais por el Carmen le diréis a dicho padre se lo pida, supuesto no lo ha presentado. A ésta que dejará ahí el mozo le pondréis un sobre de letra de Polanco para Eugenio Martínez. Pero primero, como digo, que lo vea don Julián Monzón y... el abogado Auñón, si se ofrece o gustáis que lo vea, pero decirle que yo he declarado que sólo un desliz, pero que ella está firme en declarar no he sido yo, y que ya tengo todo prevenido a Mazarulleque (carta de Juan José Aranda, cura, a su cuñado José Antonio Aranda y José Polanco, fechada entre 1756 y 1757).

(13) Hijo mío. De sumo gusto será para mí que estéis buenos. Por acá todos la gozamos, a Dios las gracias (carta de Petronila González a su marido, Pablo Díez, boticario, fechada el 11 de septiembre de 1709).

(14) Y aunque hubiese quien los protegiese, serían inútiles sus conatos. Por lo que, vista la inacción del corregidor en dar cumplimiento a una orden del Consejo tan interesante, esperan $t u$ dictamen para conforme a él hacer lo que digáis, aunque en el entretanto no cesarán de interpelar al escribano y practicar cuanto alcance su cortedad y permitan las circunstancias del juzgado para hacer ver al Consejo su justicia (carta de Francisco Andújar Caballero, labrador, a su hijo, Juan de Dios Andújar, escribano, fechada el 3 de enero de 1798).

En todos los ejemplos anteriores, no sólo se constata ese cambio de flexión según el alocutario, sino que se certifica que es la forma T la empleada en la cercanía y la jerarquía familiar por quien está en la posición superior, ya sea en singular con la forma tú más la 2sg. o en plural con vosotros más la 2pl.

En el caso de los treinta y tres años del siglo xix que comprende el corpus utilizado, observamos el mismo comportamiento pragmático que en la centuria anterior; el uso de vosotros es plural, va alternando con tratamientos singulares, según el 
alocutario al que se refiera el autor, y se dirige a amigos o algunos familiares (15-19):

(15) PD Como no he sabido nada de vosotros desde que nos despedimos, ignoro si llegó Gregorio cuando le esperabais. De todas maneras, lo supongo ya en vuestra compañía y vivo con la esperanza de que nos haga una visita (carta de José Mazarrasa y Cobo a su hermano Felipe Mazarrasa y Cobo, fechada el 22 de septiembre de 1833).

(16) Además yo le escribí directamente a ésa bajo su sobre avisándole que recogiese las otras. Este atraso es de la mayor transcendencia y si no está ahí recógelas tú y haz lo que en ellas te se dice inmediatamente, pues corre mucha prisa, mucha, mucha.

Yo he procurado saber de vosotros por mis caminos; y aun el general Lacerda, que está en la Guardia, ha debido recibir aviso sobre $t i$ (carta de Pedro Nicanor González a Mateo Villaverde, fechada el 14 de septiembre de 1827).

(17) En fin, amigo mío, la obra no sería grande si no costase tanto. Yo he perdido mucho y tengo mucho que esperar si no nos lleva el diablo, que es irme a mi casa y echarlos a todos a paseo, como hacía antes. Por consiguiente, que no envidien el puesto... Nuestro Señor os conserve en su santa gracia, os libre de rayos y centellas y os dé el descanso. Os deje comer en sosiego la racioncita, los 6 vintencitos e ir pasando hasta empuñar la tizona, para cuyo día no sé si podréis contar con otros camaradas que los que se parezcan a vuestro amigo (carta de Pedro Nicanor González a Manuel López, fechada en 1827).

(18) A doña Micaela la han vencido a la compostura de todo el pleito. Ignoro quién ha sido. Sólo desean la paz. Así me ha puesto recado que lo componga yo por su parte. Yo la he dicho me veré con ella. Y deseoso de vuestra vejez sea quieta y os quede para poder vivir sin consumirlo todo en pleitos, pues no es regular que lo que a mi tío le costó tantos desasosiegos en adquirirlo lo vendáis para semejantes enredos, yo voy a aceptar el encargo movido por el temor de Dios y bien de vosotros (carta de Ramón Montero a su primo Manuel Sanz Martínez, fechada el 28 de abril de 1820).

(19) Mi estimado Francisco. Celebraré el que ésta te halle completamente restablecido e igualmente a toda la familia. Sentí 
mucho vuestras indisposiciones y me alegro de la mejoría. Yo voy pasando muy bien, a Dios gracias.

Recibí por hermano Casiano la camisa y los calzoncillos. Dios os premiará la caridad que ejercitáis conmigo. Ahora para principiar la Santa Cuaresma me enviarás dos libras de chocolate. Y perdonar las molestias que os ocasiono. Recibe mis expresiones y dárselas a $t u$ parienta y familia y a todos etc. (carta de Antonio Sánchez Ornero a Francisco Romero Salazar, fechada el 18 de febrero de 1803).

Sin embargo, a pesar de estos ejemplos, han aparecido ocurrencias en las que se seguía empleando vos incluso para un solo interlocutor, combinándose con flexión de 2 pl., aunque en alternancia con otros tratamientos pronominales y verbales tuteantes y ustedeantes (20-25):

(20) Y después volví a la turbación, de modo que el diablo le dijo a uno de los ministros estas palabras: - Oye tú, ministro. Cuidado de hacer con reverencia eso que has hecho, porque si no os enmendáis llegará día que no se os deje salir al altar (carta de Atanasio Martínez a Francisco Villalón, fechada entre 1795 y 1805$)$.

(21) Anda buscando fiador. Juzgo que le hallará. Estotro día echaba a menos el saber de $t i$ : es buen amigo. Puntual eres en llamándote. De noche antes de dormirme os llamo para que amemos a Dios y en la misa hay mucha puntualidad en asistir (carta de Manuel de Santa Leocadia, religioso, a Pablo Díez, boticario, fechada el 15 de enero de 1708).

(22) Un gran señor y consejero se halla en muy gran peligro por algunos que le trazan traición con falsedad y os suplico os acordéis de él en vuestras oraciones y obras santas, pues soy seguro que si vos lo tomáis a vuestro cargo para con Dios... Y si fuese caso que os llamen a Madrid, ande VM con cuidado, pues tendrá VM mucho peligro de la vida (carta de Bernardo Gómez Velasco a sí mismo, fechada el 28 de diciembre de 1768).

(23) Tú me ordenaste, Señor, que pida licencia, y la tengo; pero de tus brazos, Dios mío, han de pasar los míos a hacer lo que vos queréis. Y habéis de ser mi fiador en todo, pues sois buen navío y no quiero que haya borrasca de amor propio mío (carta de Manuela Ramos a fray Francisco Fernández y Villegas, sacerdote y prior, fechada entre 1700 y 1709). 
(24) Quejábame al Señor y le decía: "Padre y Señor mío, ¿qué mal te he hecho yo para que me hayáis puesto de esta manera?" Mire VM qué buena hija de Dios soy, pues le decía que qué mal había yo hecho, pues quien no le ha servido en nada a quien tanto he debido (carta de Manuela Ramos a fray Francisco Fernández y Villegas, religioso, fechada el $1^{\circ}$ de enero de 1704).

(25) Cuéntase por cierto que, viendo un buen hombre en una Semana Santa el paso de Nuestro Señor que a caballo en un jumento entraba en Jerusalén, se puso de rodillas e hizo esta deprecación:

¡Asno que a mi Dios lleváis, ojalá yo fuera vos! Suplícoos, Señor, me hagáis como ese asno en que vais. Y dicen que le oyó Dios (carta de Antonio Torres, presbítero y secretario del obispo, a una religiosa de San Bernardo, fechada el 5 de diciembre de 1780).

Al cotejar las muestras (20-25), observamos que el estilo utilizado no se corresponde con el registro coloquial: o bien se dirigen a Dios, o bien presentan un estilo literario arcaizante, o bien sus autores pertenecen al ámbito eclesiástico, y ni siquiera quien remite es consecuente con alguna de las opciones, ya que recurre al tuteo o al usted en determinados pasajes. Incluso en (26), el documento original presenta el empleo de vos en voladita, como uso arcaizante, ya que el tratamiento general es el de vuestra merced:

(26) Y perseguiré mi justicia como caballero volviendo por mi punto y haciendo que, si él me hubiera conocido, no se cegara. Y aunque he sabido lo poco que nos ha creído esto, sepa es mucha verdad; y que se lo he probado con mejores testigos de los que él se valió en la sumaria con jurados solicitados y amenazados; y a otros haberles supuesto sus dichos, el saqueo y robo de mi casa en lo que he dicho con el seguro de echar de ella mi familia y entrarla a vivir los muchos estafos a vos. He querido decir a VM esto por las noticias que he tenido de lo que volvía... contra esta verdad y para que se desengañe (carta de Gregorio Páez, caballero del hábito de Santiago, a Antonio Mojica, fechada el 3 de octubre de 1707).

Estos usos de vos dejan de aparecer en las misivas del siglo XIX. En cualquier caso, los datos de 1409 cartas que hemos analizado apuntan a que el uso de vosotros o sus formas concordantes 
era mínimo, en comparación con ustedes, que representaba la forma no marcada de cortesía incluso entre amigos o familiares. El empleo de vosotros se ha utilizado en nuestro caso entre personas que tenían un vínculo familiar simétrico, de padres a hijos o entre amigos o personas que compartían una relación próxima. Además, el origen y residencia de los autores de las misivas se circunscriben al centro-norte peninsular e incluso a la zona levantina. De hecho, si consultamos a Casanovas y Ferrán (1833), observamos que, hablando de cómo tratan los padres a los hijos si han de referirse a éstos en plural (ya que en singular los tutean), indica que los catalanes usan vosotros, mientras que en Andalucía y Castilla se recurre a ustedes. Vistos los datos, pasamos a continuación a analizar la casuística que hemos hallado.

\section{ANÁlisis Y DISCUSIÓN}

Los datos extraídos del corpus Post scriptum certifican los últimos conatos de vos singular en España, acotados a la retórica religiosa o como estrategia arcaizante. Estos vestigios se diluyen en época dieciochesca y su aparición no comporta siempre la 2pl., ya que los mismos usuarios que lo emplean alternan con el tuteo o la abreviación VMy la 3sg. Por lo demás, las ocurrencias referidas a vosotros como pronombre o sus elementos flexivos señalan que no eran desconocidas entre las clases menos favorecidas de la primera etapa borbónica, con una profusión mayor en el centro-norte peninsular y la zona levantina. Estos usos no son iguales a los que se daban en el mismo lapso temporal en América. Para la variedad americana, remitimos a los trabajos de Calderón Campos (2019) y Bertolotti (2020), pero para entender la casuística del español peninsular, es pertinente comparar los datos con otros estudios realizados.

Indicamos en la introducción que Fernández Martín (2012) había demostrado que, en el siglo XVIII, la disyuntiva vosotros-ustedes no se había asentado completamente en España, pues reflejaba hibridaciones en la concordancia verbal y pronominal asociadas a ustedes (pero no a vosotros) que estaban generalizadas en todo el país. Explicamos asimismo que, según Lara Bermejo (2018), esta misma oposición estaba completamente asumida en la primera mitad del siglo $\mathrm{xx}$, sin que hubiera discordancias entre pronombre y elemento concordante, salvo en Andalucía occidental, donde imperaba una nivelación al estilo 
americano, aunque con mezclas flexivas entre la $2 \mathrm{pl}$. y la $3 \mathrm{pl}$. $\mathrm{El}$ aumento de vosotros coincide por tanto con el período comprendido entre los siglos XVIII y XIX, en los que España es testigo de una nueva moda pragmática en la que va primando la solidaridad frente a la deferencia y la jerarquía que dominaron en las centurias previas. Además, en todas las innovaciones basadas en esta tendencia solidaria, el camino geográfico y sociolingüístico es idéntico: el área centro-norte por imitación de Francia y la clase alta como iniciadora del cambio, aunque con el concurso del estrato de clase media como difusora de tales modificaciones en todo el espectro social. Estas nuevas propuestas suben exponencialmente a partir de la Revolución francesa, según Brown y Gilman (1960), ya que la solidaridad empieza a percibirse como sinónimo de libertad, igualdad, fraternidad y democracia, en consonancia con los regímenes liberales y como contestación a la realidad jerárquica y deferencial del Antiguo Régimen. Los datos que hemos expuesto aquí marcan los primeros indicios de solidaridad en el español hablado en la Península Ibérica.

Antes de analizar el binomio vosotros-ustedes, queremos llamar la atención de dos fenómenos concomitantes: el tuteo como forma no marcada de cortesía y la solidaridad en el ámbito familiar junto con los apelativos mamá y papá. García Godoy (2010) apunta al siglo xIX como etapa en la que las élites madrileñas incorporaron la moda francesa de llamar papá y mamá a sus progenitores, preludio del tuteo que vendría a posteriori para esos interlocutores. Estos usos se extendieron por toda España y llegaron tarde a Andalucía, donde se mantuvieron por más tiempo las formas padre y madre más usted. Molina Martos (2020) refrenda lo descubierto por García Godoy y añade que el tuteo generalizado empieza a finales del siglo xIx y se asienta en España en la primera mitad del siglo xx, de tal manera que tú sirve para el trato familiar, para el trato entre amigos y para el trato entre superiores e inferiores. El tuteo, desde entonces, no ha dejado de intensificarse ante el empleo de usted, precisamente por las razones esgrimidas antes: se relaciona con la idea de solidaridad, de igualdad, de libertad, de democracia, de amistad. No obstante, este tuteo por defecto arriba más tarde a Andalucía, donde usted como término no marcado de cortesía permanece durante más tiempo (Calderón Campos 2010). Este tuteo que las clases acomodadas del centro-norte incorporan es contagio directo de las modas galas que se habían producido 
a partir de la Revolución francesa; es más, la prensa de finales de la centuria de 1700 empieza a llamar la atención sobre esta nueva particularidad (Lara Bermejo 2020). El triunfo de la dinastía Borbón, de origen francés, tras la Guerra de Sucesión Española (1700-1714), supuso la instauración de un nuevo prestigio que se asociaba con Francia. Todo aquello que imitaba los gustos galos era emulado por los acomodados de la época, como manera de congraciarse con la nueva clase dominante. Este prestigio galo no se dio únicamente en España, sino que significó un fenómeno paneuropeo, cuya máxima expresión, según Joseph (1987), fue el empleo del francés como lengua de comunicación y de referencia entre la clase alta centroeuropea y rusa, incluidas las distintas casas reales. Es más, la oposición rusa entre ty-wy como formas $\mathrm{T}$ y $\mathrm{V}$ es contagio directo del tándem tu-vous del francés.

El uso de vosotros, aunque documentado en la clase baja en este artículo, fue sobre todo innovación de la corte madrileña una vez que se asentaron los Borbones, según señala Fernández Martín (2012). Sin embargo, el aumento de vosotros a más contextos que en siglos anteriores se enmarca en una tendencia hacia la solidaridad, que también se dio en las demás lenguas de España, como el gallego y el catalán. Ya apuntamos que Casanovas y Ferrán (1833) se sorprendía por el eminente uso de vosotros en Cataluña frente a Castilla —además, todos los perfiles geográficos de nuestro corpus muestran hablantes del centro-norte peninsular, frente a la inexistencia de andaluces. El tuteo generalizado, los términos papá y mamá a costa de padre y madre, así como su aumento en los ámbitos donde se utilizaba vosotros, se dieron en primera instancia en el centro-norte peninsular, independientemente de la lengua hablada, y sólo más tarde comenzaron a penetrar en Andalucía, a tal punto que el binomio vosotros-ustedes seguía sin resolverse en el siglo xx, aunque con aparente nivelación a favor de ustedes, cuyas posibilidades de concordancia se ceñían a la 2pl. y la 3 pl.

La disonancia entre Andalucía y el resto de España es pertinente para entender el sistema del español peninsular y el de América. O'Flanagan (2008) escudriña la historia de las zonas portuarias del Atlántico peninsular desde 1500 hasta $1900 \mathrm{y}$ revela datos interesantes para entender las consecuencias lingüísticas y pragmáticas de las que hablamos. Ante todo, el autor subraya que España estaba lejos de disfrutar de unidad nacional tal cual se entiende hoy en día. Las divergencias territoriales 
entre zonas era la norma, y ni la unión de los Reyes Católicos, ni de sus descendientes, cambiaron dicha particularidad. O'Flanagan (2008) apunta al monopolio que se concedió al eje SevillaCádiz como prueba de ello, ya que tan sólo benefició a esa comarca, pero no repercutió ni en un adelanto de las comunicaciones con el resto de España ni en una mayor unión con otros territorios castellanoparlantes de la Península Ibérica. El microcosmos nacido de este hecho histórico se concentró entre el suroeste y las respectivas colonias, pasando por las islas Canarias, que hacía de enclave secundario en la ruta comercial. En otras palabras: había mayor comunicación y reciprocidad entre América, Canarias y Sevilla-Cádiz que entre estas dos ciudades y Madrid u otra localidad importante del centro o del norte.

La interconexión transatlántica se vio con mayor fuerza durante la decadencia del imperio a partir de la Guerra de Sucesión Española. Cádiz se volvió el centro administrativo del negocio colonial y Sevilla fue experimentando un declive paulatino al que se unió también la zona gaditana tras las independencias. En cambio, los receptores marítimos del norte peninsular, que habían compartido un estatus inferior en comparación con sus homólogos meridionales y apenas habían aceptado negocio de orígenes americanos, se concentraban en intercambios con Francia, Reino Unido o Hamburgo. Una vez en territorio español, los intercambios se ampliaban con la zona de Castilla y Madrid, que siempre se había caracterizado por mantener mayores relaciones con la zona norte que con el emporio de Sevilla.

O’Flanagan (2008) no sólo se concentra en números de importaciones y exportaciones, sino que analiza las consecuencias demográficas y migratorias de cada uno de los puertos y sus zonas colindantes, apuntalando los intercambios constantes de población entre el suroeste y América, frente al establecido entre el norte con Castilla, Madrid y los países europeos cercanos. Además, el investigador resalta que, a partir de finales del siglo XVIII, con un aumento gradual en el xix y un auge exponencial a finales de 1800 y principios de 1900, los puertos del norte peninsular crecieron en importancia y multiplicaron su interdependencia con Europa y su proximidad con Madrid. En todas estas zonas de España y del resto de Europa se produjeron simultáneamente los siguientes fenómenos: creció la solidaridad pragmática, se impusieron los galicismos mamá y papá y, en menor medida, la 2 pl. y sus pronombres se generalizaron por imitación del vous francés (Brown \& Gilman 1960; 
Helmbrecht 2005); véase, sin ir más lejos, la generalización de you en inglés, que es en origen un pronombre de $2 \mathrm{pl}$. (Raumolin-Brunberg 2005). En el caso de España, el pronombre elegido fue vosotros, al ser la única posibilidad que se tenía en plural y que, a su vez, indujera morfología de 2 pl. sin estar condenada por décadas de declive. Es decir, en lugar de elegir vos, la solidaridad en plural se configuró mediante el pronombre vosotros, que, además, coincidía con el comportamiento flexivo de vous en francés.

Hemos indicado que, aunque la clase alta es la instigadora de dichos cambios, en gran parte de ellos fue la clase media la que los popularizó para toda la sociedad. Este estrato, nacido de las nuevas realidades surgidas tras la Revolución francesa y la industrialización, así como el éxodo del campo a la ciudad, fue el responsable de generalizar el tuteo como forma no marcada de cortesía, frente al empleo por defecto de usted. Así lo constata Molina Martos (2020), al argüir que la clase media contagió a la clase baja el tuteo de hijos a padres, mientras que condicionó que la clase alta usara el tuteo en situaciones de amistad o proximidad simétricas. La formación del binomio vosotros-ustedes parece responder igualmente a la existencia de la clase media, ya que no sólo podría haber irradiado el empleo de vosotros que Fernández Martín (2012) achaca a la clase alta del centro-norte peninsular, sino también el uso de vosotros que se observa en la clase baja, analizado en el presente estudio. De momento, no es posible corroborar esta hipótesis con los datos que hemos expuesto, pero sí podemos certificar una situación análoga a la del tuteo descrita por Molina Martos (2020) para los años 1800. De confirmarse, el tuteo no sería sólo un fenómeno en singular, sino que se habría dado también en plural encarnado en el pronombre vosotros.

Todas estas innovaciones se impusieron en Andalucía en una época en la que las posesiones americanas se independizaban de España, por lo que las modas de la metrópoli nunca llegaron al otro lado del Atlántico. Es más, en nuestro corpus no hay ni una sola ocurrencia de vosotros en hablantes de Andalucía. El devenir de vosotros en el continente americano fue su paulatina desaparición y desplazamiento por ustedes, el cual, por lo demás, había sido la forma no marcada de cortesía, como en España, hasta los años de 1800. En el caso de este país, no obstante, se produjo un aumento gradual de dicha forma, junto con el pronombre $t u ́$, como estrategia que trata de satisfacer las 
ideas liberales y democráticas. Esta misma presión se ve incluso actualmente en Andalucía occidental, donde la nivelación va en claro retroceso favoreciendo la dicotomía entre vosotros-ustedes y un uso cada vez mayor del primer pronombre, en consonancia con el resto del español peninsular (Lara Bermejo 2018).

\section{Conclusiones}

Los datos extraídos del corpus Post scriptum, basado en cartas privadas de los siglos XVIII y XIX, han mostrado los primeros conatos de solidaridad como tendencia no marcada de cortesía que empezó a fraguarse a partir de la Revolución francesa y la industrialización. Los resultados indican un empleo del pronombre vosotros en estratos desfavorecidos cuando existe una relación jerárquica familiar, usado siempre por los que se hallan en una posición superior (de padres a hijos, por ejemplo) o como símbolo de paridad entre familiares del mismo rango, como hermanos y primos. A pesar de estos usos, son ustedes y sus variantes las formas más extendidas en el trato a un grupo de personas, ya que el sistema de cortesía imperante en tal época era el jerárquico y deferencial.

Estos primeros usos de solidaridad coinciden con otros fenómenos análogos, como el aumento del tuteo o la incorporación de mamá y papá a costa de madre y padre, lo cual se dio en primera instancia en el área centro-norte peninsular y levantina, por imitación de las modas francesas. El hecho de que se atestigüe el empleo de vosotros en la clase baja indica que su posterior popularización podría deberse al surgimiento de la clase media, que habría esparcido igualmente los usos de vosotros de la clase alta madrileña que empezaban a darse en situaciones donde antes imperaba el pronombre ustedes, tal y como aconteció con el tuteo. A este respecto, los usos incipientes de vosotros que hemos documentado son el reflejo en plural del incipiente tuteo en singular, ya que, reiteramos, la solidaridad empieza a cobrar especial relevancia a partir de esta época.

Por último, queremos resaltar los postreros vestigios de vos singular, que han surgido alrededor del mundo eclesiástico o como estrategia arcaizante, pero que ya no se aprecian en era decimonónica. En su lugar, el mismo informante que recurre a este pronombre, alterna entre usted y tú, en función de la relación que mantiene con su interlocutor. 


\section{REFERENCIAS}

Bertolotti, Virginia 2020. "The dismissal from vosotros in the Americas", en Address in Portuguese and Spanish. Diachrony and diachronic reconstruction. Eds. Martin Hummel \& Célia Lopes, De Gruyter, Berlin, pp. 291318.

Brown, Robert \& Albert Gilman 1960. "The pronouns of power and solidarity”, en Style in language. Ed. Thomas A. Sebeok, MIT, Cambridge, pp. 253-276.

Calderón Campos, Miguel 2000. "Fórmulas de tratamiento en las cartas del conde de Tendilla (1504-1506)", en Actas del V Congreso Internacional de Historia de la Lengua Española. Eds. María Teresa Echenique y Juan Sánchez Méndez, Arco/Libros, Madrid, pp. 477-487.

Calderón Campos, Miguel 2010. "Los elementos nominales en el sistema de tratamiento del español de Andalucía durante la Restauración (18751931)", en Formas y fórmulas de tratamiento en el mundo hispánico. Eds. Martin Hummel, Bettina Kluge y María Eugenia Vázquez Laslop, El Colegio de México-Karl-Franzens-Universität Graz, México, pp. 551-570.

Calderón Campos, Miguel 2019. "Pérdida del pronombre vosotros y su paradigma”, en Estudios de morfosintaxis histórica hispanoamericana. T. 1: El pronombre. Eds. Juan Pedro Sánchez Méndez, Antonio Corredor Aveledo y Elena Padrón Castilla, Tirant Humanidades, Valencia, pp. 125-162.

Casanovas y Ferrán, JoAQUín 1833. Colección de vocablos y modismos incorrectos y viciosos usados por los catalanes cuando hablan el castellano y tomados al oído o leídos en periódicos y libros: materias diversas sobre el lenguaje. Nociones de ortografía, Luis Tasso y Terra, Barcelona.

De Jonge, Bob y Dorien Nieuwenhuijsen 2006. "Formación del paradigma pronominal de las formas de tratamiento", en Sintaxis histórica de la lengua española. Segunda parte: La frase nominal. Coord. Concepción Company, Universidad Nacional Autónoma de México-Fondo de Cultura Económica, México, vol. 2, t. 2, pp. 1593-1672.

Fernández Martín, Elisabeth 2012. La oposición "vosotros"/ "ustedes" en la historia del español peninsular (1700-1931), Universidad de Granada, Granada.

FERnÁndez-Ordóñez, Inés 2011. La lengua de Castilla y la formación del espanol, Espasa, Madrid.

García, Érica, Robert de Jonge, Dorine Nieuwenhuijsen y Carlos LechNER 1990. "(V) os-(otros): ¿dos y el mismo cambio?", Nueva Revista de Filología Hispánica, 38, pp. 63-132; doi: 10.24201/nrfh.v38i1.774.

García Godoy, María Teresa 2010. "El tratamiento a los progenitores en el español peninsular (siglo XIX). Contraste de dos variedades geográficas", en Formas y fórmulas de tratamiento en el mundo hispánico. Eds. M. Hummel, B. Kluge y M.E. Vázquez Laslop, El Colegio de México-Universität Karl-Franzens Graz, México, pp. 595-617.

García Godoy, María Teresa 2015. "El cambio vuestra merced $>$ usted desde la documentación archivística", en Temas, problemas y métodos para la edición y el estudio de documentos hispánicos antiguos. Eds. Juan Pedro Sánchez Méndez, Mariela de la Torre y Viorica Codita, Tirant Humanidades, Valencia, pp. 661-694. 
García Godoy, María Teresa 2016. “¿Fue vulgar y plebeyo el origen de usted? La diacronía del pronombre de respeto desde la interfaz oral/ escrito", Oralia, 19, pp. 61-84.

Gomila Albal, Marina 2016. "Sobre el origen y la difusión geográfica de las formas nosotros y vosotros en castellano", Iberoromania, 83, pp. 103-125; doi: 10.1515/ibero-2016-0008.

Helmbrecht, Johannes 2005. "Typologie und Diffusion von Höflichkeitspronomina in Europa", Folia Linguistica, 39, 3/4, pp. 417-452; doi: 10.1515/flin.2006.39.3-4.417.

JOSEPH, JOHN EARL 1987. Eloquence and power: The rise of language standards and standard languages, Burns and Oates, London.

Lara Bermejo, Víctor 2018. La cortesía en la Península Ibérica: dialectología del Sprachbund suroccidental, Peter Lang, Bern.

Lara Bermejo, Víctor 2020. "Actitudes hacia el tuteo en la España borbónica”, en Creencias y actitudes ante la lengua en la España y América de los siglos XVIII y XIX. Eds. Manuel Rivas y Victoriano Gaviño, Iberoamericana-Vervuert, Madrid-Frankfurt/M., pp. 175-192.

Molina Martos, Isabel 2020. "Linguistic change and social transformation: The spread of tuteo in Restoration Spain and Second Republic (1875-1939)", en Address in Portuguese and Spanish. Studies in diachrony and diachronic reconstruction. Eds. M. Hummel \& C. Lopes, De Gruyter, Berlin, pp. 443-480.

O'Flanagan, Patrick 2008. Port cities of Atlantic Iberia c. 1500-1900, Ashgate, Aldershot.

Pla CÁrceles, José 1923. "La evolución del tratamiento de vuestra merced", Revista de Filología Española, 10, pp. 245-280.

Post scriptum = CLUL 2014 [en línea]. P.S. Post scriptum. Arquivo digital de escrita quotidiana em Portugal e Espanha na Época Moderna, http:/ /ps.clul.ul.pt. [consultado el 11 de octubre de 2019].

Raumolin-Brunberg, Helena 2005. "The diffusion of subject you: A case study in historical sociolinguistics", Language Variation and Change, 17, pp. 55-73; doi: 10.1017/S0954394505050039.

Scollon, Ron \& Suzanne Scollon 1995. Intercultural communication. A discourse approach, Blackwell, Malden.

Tuten, Donald 2008. "Factores socioculturales en el desarrollo de vuestra merced/ usted", en Actas del VII Congreso Internacional de Historia de la Lengua Española. Eds. Concepción Company y José Moreno de Alba, Arco/ Libros, Madrid, pp. 2189-2199. 